University of South Florida

DIGITAL COMMONS

Digital Commons @ University of

@ UNIVERSITY OF SOUTH FLORIDA

South Florida

$5-1985$

\title{
Equatorial Atlantic Velocity and Temperature Observations: February-November 1981
}

Robert $\mathrm{H}$. Weisberg

University of South Florida, weisberg@marine.usf.edu

Follow this and additional works at: https://digitalcommons.usf.edu/msc_facpub

Part of the Marine Biology Commons

\section{Scholar Commons Citation}

Weisberg, Robert H., "Equatorial Atlantic Velocity and Temperature Observations: February-November 1981" (1985). Marine Science Faculty Publications. 139.

https://digitalcommons.usf.edu/msc_facpub/139

This Article is brought to you for free and open access by the College of Marine Science at Digital Commons @ University of South Florida. It has been accepted for inclusion in Marine Science Faculty Publications by an authorized administrator of Digital Commons @ University of South Florida. For more information, please contact digitalcommons@usf.edu. 


\title{
Equatorial Atlantic Velocity and Temperature Observations: February-November 1981
}

\author{
R. H. WEISBERG \\ Department of Marine Science, University of South Florida, St. Petersburg, FL
}

(Manuscript received 20 September 1983, in final form 21 January 1985)

\begin{abstract}
Upper ocean velocity and temperature measurements were obtained in the central equatorial Atlantic using surface moored current meters from February to November 1981. Distinct seasonal variations were observed in the zonal momentum and temperature on the equator of both the surface South Equatorial Current (SEC) and the subsurface Equatorial Undercurrent (EUC). After initially intensifying during boreal spring the SEC halted abruptly in early summer and the signature associated with this change progressed westward. At the observational depth of $100 \mathrm{~m}$ both speed and temperature increased during early summer with eastward progression and then decreased in fall. Higher frequency motions were also modulated by the seasonal cycle. Notable were the 2-3 week time scale oscillations of the meridional velocity component which appeared most energetically during the summer and fall seasons. Oscillations generally tended to be anisotropic and inhomogeneous. Vertical advection of zonal momentum was an important term in the momentum balance of the zonal velocity component fluctuations.
\end{abstract}

\section{Introduction}

In preparation for the Seasonal Response of the Equatorial Atlantic (SEQUAL) experiment two surface moorings were maintained in the central equatorial Atlantic from February through November 1981. This paper presents the velocity and temperature data gathered by these preliminary SEQUAL moorings on the equator within the South Equatorial Current (SEC) and the Equatorial Undercurrent (EUC). The field program and data are discussed in Sections 2 and 3 respectively. Distinct seasonal variations were observed in the velocity components and temperature time series as shown in Section 4. Sections 5 and 6 address the kinematics of the higher frequency velocity and temperature fluctuations and their vertical coherencies. Certain aspects of the momentum balances as calculable from the data are discussed in Section 7 and Section 8 provides a summary.

\section{Field program}

Taut wire surface moorings, fashioned after those of Knox and Halpern (1982) were used to suspend Vector Averaging Current Meters (VACMs) in the upper $250 \mathrm{~m}$ of the water column as shown in Fig. 1. Two deployments of two moorings each were made. The first deployment was accomplished from the R/V Endeavor with a total of 10 VACMs. These were recovered in May 1981 aboard the same vessel and replaced with similar moorings having a total of 6 VACMs. Final recovery was accomplished aboard the R/V Gyre. Launch, recovery, and data return information are summarized in Table 1. Record numbers which will appear on subsequent figures are keyed upon instrument depth. Data returns on the first set of deployments were excellent. On the second set, one record was lost due to an electronic malfunction and velocity data was cut short on three records due to bearing failures.

\section{Data}

Time series of the velocity components and temperature, low pass filtered to remove tidal and higher frequency fluctuations, are shown in Fig. 2. North and east are the normal coordinates within the equatorial waveguide as shown analytically by Matsuno (1966) and as supported observationally by Horigan and Weisberg (1981). Weisberg and Horigan (1981) found a frequency separation between fluctuations occurring in the north and east velocity components ( $v$ and $u$ respectively) in the abyssal equatorial waters with the $v$-component oscillations confined to time scales of a month and shorter while the $u$-component oscillations occurred over lower frequencies. Similar behavior occurs here in the upper equatorial ocean. The $u$-component undergoes a seasonal cycle while the $v$-component oscillates at higher frequencies. Mean values and standard deviations for $u, v$ and $T$ calculated separately for each deployment are shown in Fig. 3. The $u$ plot indicates a westward flowing SEC above $25 \mathrm{~m}$ and an eastward flowing EUC within the thermocline between 25 and $200 \mathrm{~m}$. During the second deployment the eastward flow increased at 100 and $150 \mathrm{~m}$ and the vertical temperature gradient within the thermocline decreased. Over both deploy- 

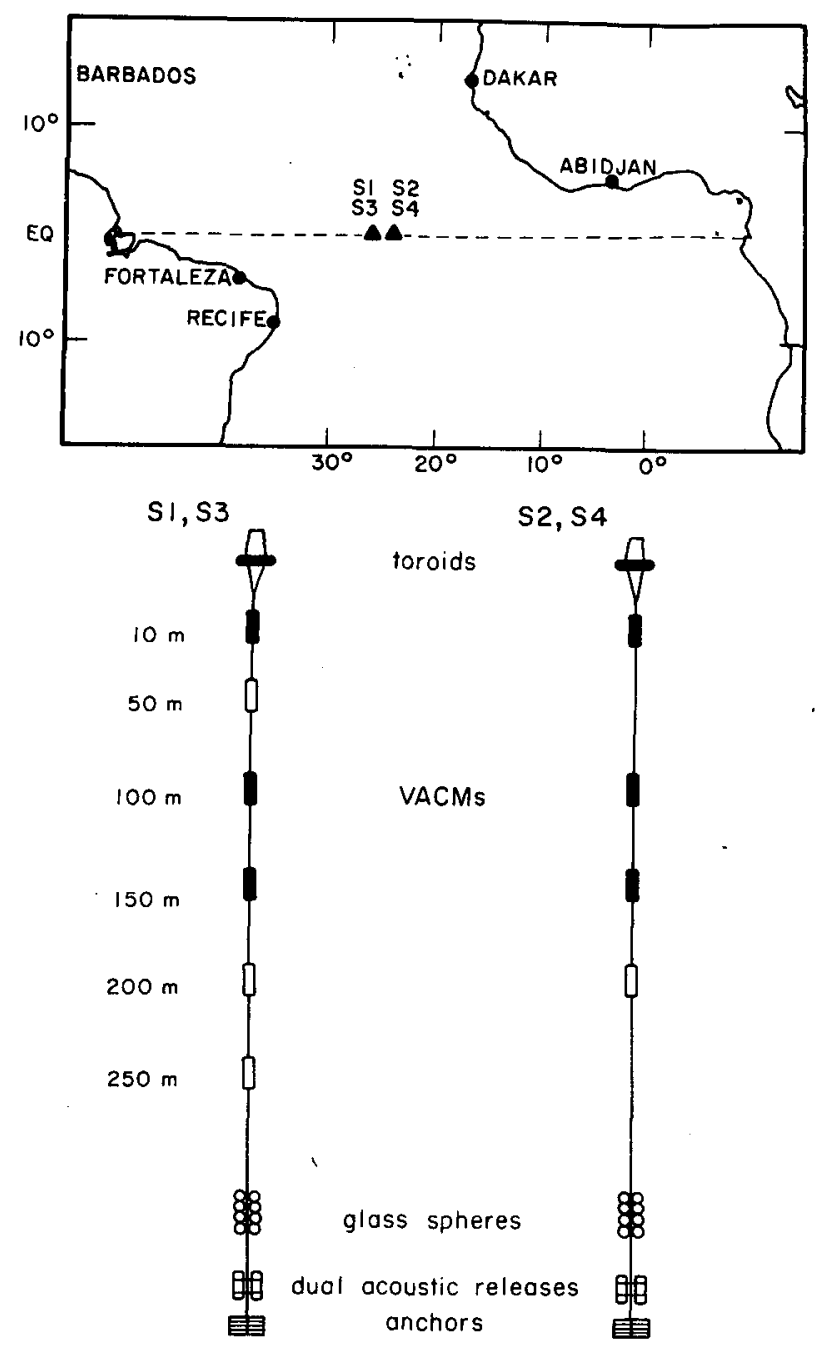

FIG. 1. Mooring locations and schematics. Unshaded instruments were not available for the second deployment.

ments, the $v$-component means were not significantly different from zero.

To approximate the vertical shape of the EUC, fifth degree polynomials were fit on a daily basis to the low-pass filtered $u$-components of mooring S1. These provided smooth curves with monotonic second derivatives across the EUC core and they were used for estimating the depths of the $20 \mathrm{~cm} \mathrm{~s}^{-1}$ isotachs and the EUC core, the speed at the core, and the integrated zonal volume transport per unit width between levels bounded by the $20 \mathrm{~cm} \mathrm{~s}^{-1}$ isotachs. Figure 4 shows the variability in the vertical position and extent of the EUC from February-May 1981. The $20 \mathrm{~cm} \mathrm{~s}^{-1}$ isotach's as interpolated from the polynomials were confined between $180 \mathrm{~m}-20 \mathrm{~m}$, the lower bound varying from $140-180 \mathrm{~m}$ with a mean at $160 \mathrm{~m}$, and the upper bound varying between 20 $50 \mathrm{~m}$ with a mean at $30 \mathrm{~m}$. One exception to the upper bound was around 1 April when the eastward speed at the surface actually exceeded that at $50 \mathrm{~m}$ as observed directly from the data. The core, as defined by the estimated depth of the $u$-component maximum, ranged between $50-100 \mathrm{~m}$ centered upon approximately $85 \mathrm{~m}$. Corresponding changes in the $u$-component estimated at the EUC core relative to that measured at $100 \mathrm{~m}$ and the integrated zonal transport per unit width on the equator are shown in Fig. 5. Figures 4 and 5 suggest that the EUC core was located above the $100 \mathrm{~m}$ observational depth from February to May 1981. Corroboration is given by the phase relationship between the $u$-component and temperature. With the vertical curvature of the EUC core being negative, vertical translation of the core together with a positive temperature gradient would result in an in phase correlation for $u$-component and temperature fluctuations if $u$ were to be observed below the core level and an out-of-phase correlation if $u$ were to be observed above the core level. Noting that the $u, T$ correlation at $100 \mathrm{~m}$ is in phase over both deployments at all observed time scales leads to the conclusion that the $100 \mathrm{~m}$ level was below the EUC core throughout the year.

Vertically integrated zonal transport per unit width on the equator was quite variable during the spring. One notable feature is the transient increase observed in March which was accompanied by rapidly increasing temperatures at the surface and down to at least $100 \mathrm{~m}$.

\section{Seasonal cycle}

The reduced number of records and their varying lengths over the second deployment limit inference that can be drawn upon the seasonal cycle. However, both the SEC and EUC are observed to undergo large variations which will be discussed within the data set limitations. These variations are primarily in the $u$ component and temperature. The $v$-component oscillations are restricted to relatively higher frequencies.

The upper ocean equatorial circulation is principally driven by the seasonally varying trade winds. In the Atlantic, northeast and southeast trade winds, separated by the ITCZ, prevail over the western twothirds of the basin while southerlies occupy the Gulf of Guinea. Monthly averaged ship observations presented by Hastenrath and Lamb (1977) and Hellerman (1979) show the spatial and temporal evolution of the seasonal wind cycle as the ITCZ migrates latitudinally. Around March, when the ITCZ is at its southernmost position, the equatorial winds are weakest while around August, when the ITCZ is at its northernmost position, the equatorial winds are strongest. Katz et al. (1977) showed that the zonal pressure gradient along the equator at the surface varies nearly in phase with the winds, and Katz and Garzoli (1982) found qualitative agreement between equatorial velocity profile data obtained during the Global Weather Experiment and the numerical model 
TABLE 1. Launch, recovery and data returns for pre-SEQUAL moorings.

\begin{tabular}{|c|c|c|c|c|c|c|}
\hline Buoy & $\begin{array}{l}\text { Location } \\
\text { (Lat./Long) }\end{array}$ & $\begin{array}{l}\text { Depth } \\
\text { (m) }\end{array}$ & $\begin{array}{c}\text { Set } \\
\text { (time/date) }\end{array}$ & $\begin{array}{c}\text { Recovered } \\
\text { time/date }\end{array}$ & $\begin{array}{l}\text { Instruments } \\
\text { depths (m) }\end{array}$ & Record \\
\hline S1 & $\begin{array}{c}0^{\circ} 02.9^{\prime} \mathrm{S} \\
26^{\circ} 02.1^{\prime} \mathrm{W}\end{array}$ & 3696 & $\begin{array}{c}1319 \\
1 / 29 / 81\end{array}$ & $\begin{array}{c}0719 \\
5 / 10 / 81\end{array}$ & $\begin{array}{r}10 \\
50 \\
100 \\
150 \\
200 \\
250\end{array}$ & $\begin{array}{l}\text { S11 } \\
\text { S12 } \\
\text { S13 } \\
\text { S14 } \\
\text { S15 } \\
\text { S16 }\end{array}$ \\
\hline S2 & $\begin{array}{r}0^{\circ} 05.2^{\prime} \mathrm{N} \\
23^{\circ} 59.3^{\prime} \mathrm{W}\end{array}$ & 3945 & $\begin{array}{r}1536 \\
2 / 1 / 81\end{array}$ & $\begin{array}{c}1050 \\
5 / 11 / 81\end{array}$ & $\begin{array}{r}10 \\
100 \\
150 \\
200\end{array}$ & $\begin{array}{l}\text { S21 } \\
\text { S23 } \\
\text { S24 } \\
\text { S25 }\end{array}$ \\
\hline S3 & $\begin{array}{r}0^{\circ} 00.2^{\prime} \mathrm{N} \\
25^{\circ} 89.5^{\prime} \mathrm{W}\end{array}$ & 3697 & $\begin{array}{c}2139 \\
5 / 10 / 81\end{array}$ & $\begin{array}{c}1019 \\
11 / 29 / 81\end{array}$ & $\begin{array}{l}10^{*} \\
100 \\
150^{* *}\end{array}$ & $\begin{array}{l}\text { S31 } \\
\text { S33 } \\
\text { S34 }\end{array}$ \\
\hline S4 & $\begin{array}{c}0^{\circ} 04.0^{\prime} \mathrm{N} \\
24^{\circ} 00.6^{\prime} \mathrm{W}\end{array}$ & 3945 & $\begin{array}{c}0356 \\
5 / 12 / 81\end{array}$ & $\begin{array}{c}0754 \\
11 / 28 / 81\end{array}$ & $\begin{array}{l}10 @ \\
100 \ddagger \\
150\end{array}$ & $\begin{array}{l}\text { S41 } \\
\text { S43 } \\
\text { S44 }\end{array}$ \\
\hline
\end{tabular}

* Bearing failure after 2 months.

** Malfunction $=$ no data.

(a) Bearing failure after 3 months.

$\$$ Bearing failure after 3 months.

results of Philander and Pacanowski (1980) and Phi- At the $10 \mathrm{~m}$ level, at both $26^{\circ} \mathrm{W}$ and $24^{\circ} \mathrm{W}$, the lander (1981). It is within the context of this climatic SEC appears weak but highly variable through early annual cycle that the 1981 observations will be framed. May. Eastward flow actually appears during March
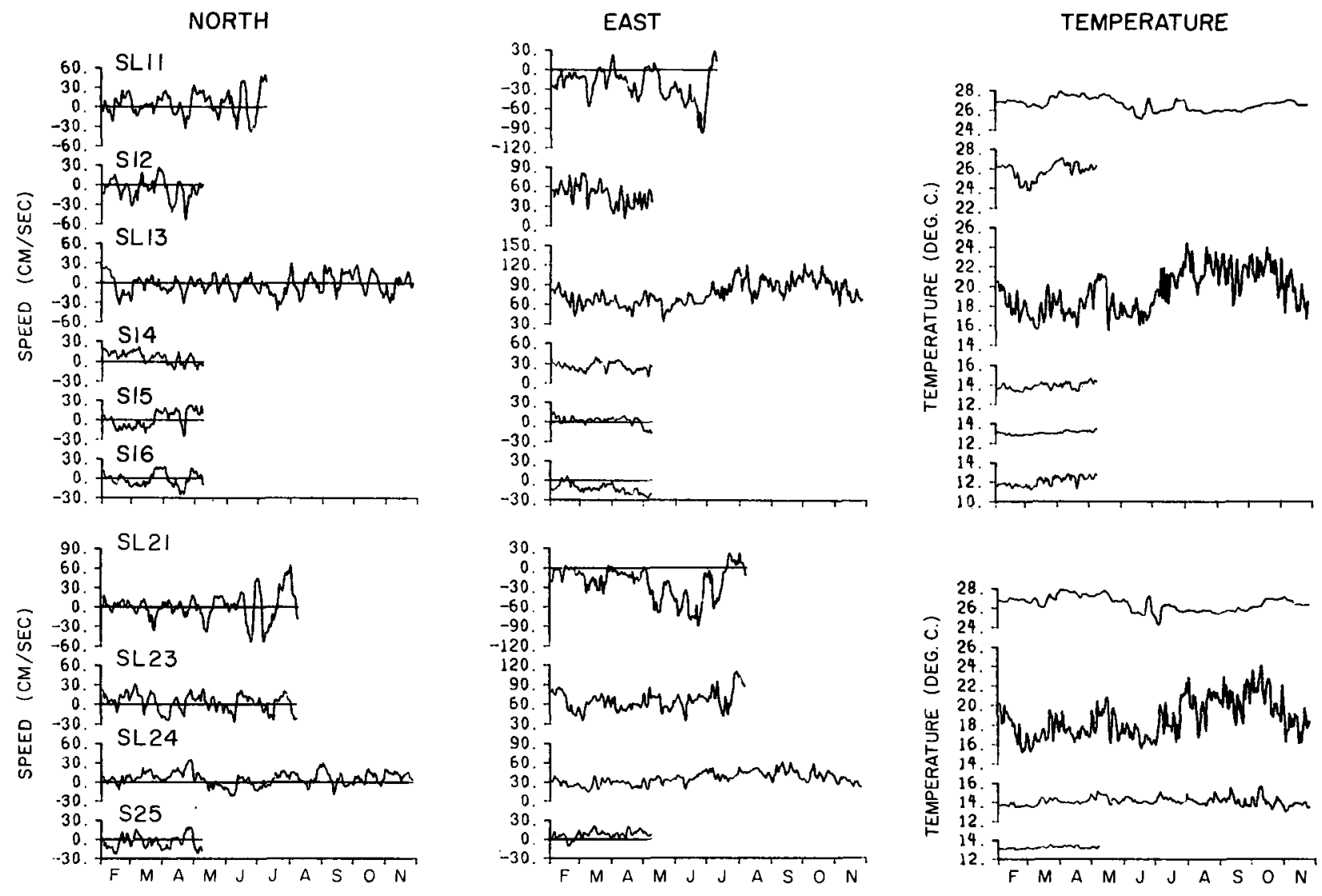

FiG. 2. Low pass filtered $(\sigma$
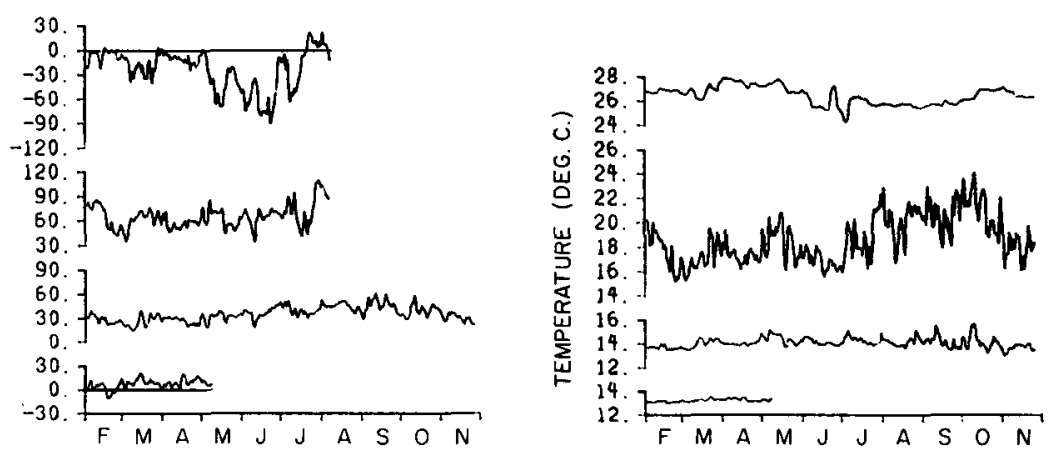

$\sigma=8 \mathrm{~h}$ Gaussian) velocity component and temperat
at $26^{\circ} \mathrm{W}$ (upper plates) and $24^{\circ} \mathrm{W}$ (lower plates). 

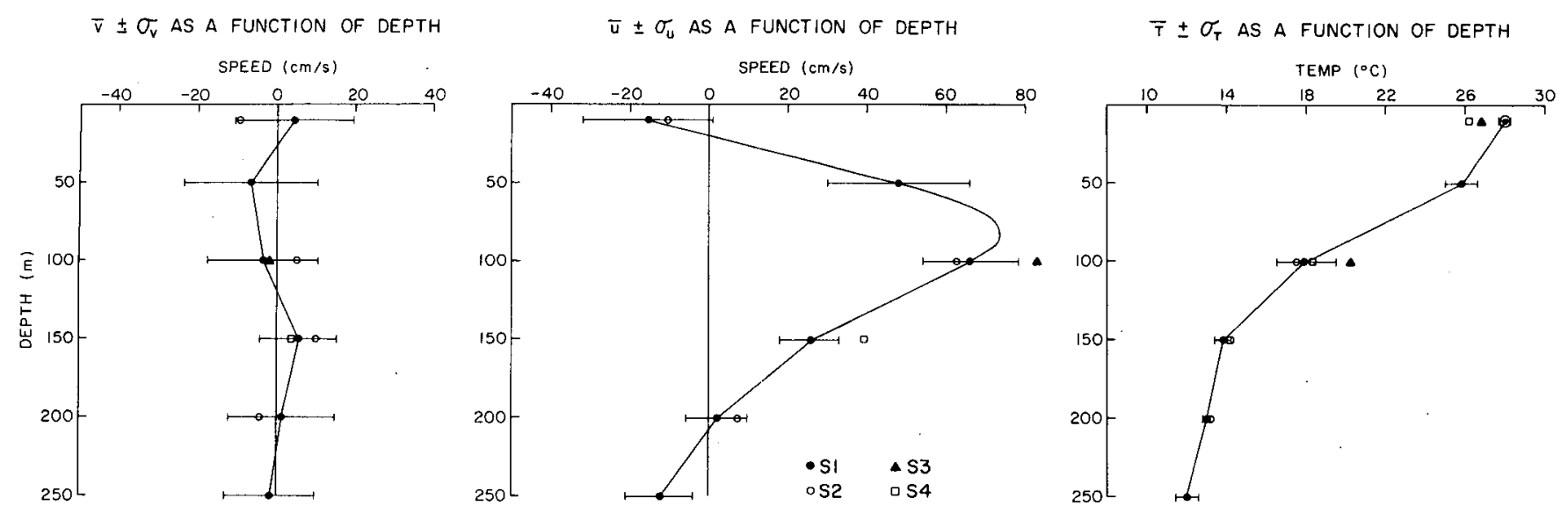

Fio. 3. Mean values and root-mean-square deviations for $v$ - and $u$-components and temperature as functions of depth computed by deployment as indicated in the legend.

with rapidly increasing temperatures at 10,50 and $100 \mathrm{~m}$. Similar behavior was observed in 1983 when simultaneous surface wind measurements (Garzoli and Katz, 1984) showed a transient cessation of easterly wind stress resulting in eastward accelerating currents and downwelling (Weisberg, 1984). Following the March event surface temperature remains steady until early May after which it decreases through midJune as the SEC accelerates westward presumably in response to increased easterlies and associated equatorial upwelling. Westward acceleration then ceases abruptly toward the end of June, the surface flow actually reverses at $26^{\circ} \mathrm{W}$ to become eastward again and the surface temperature undergoes an equally abrupt increase of more than $2^{\circ} \mathrm{C}$ followed immediately by a decrease (of more than $3^{\circ} \mathrm{C}$ at $24^{\circ} \mathrm{W}$ ). Surface temperature then remains fairly steady until mid-September when it begins to slowly increase consistent with a climatic decrease in the strength of the easterly winds resulting in equatorial convergence and downwelling. These findings are qualitatively similar to both the numerical model results of Philander and Pacanowski (personal communication, 1983) based upon climatological winds and the observations of Weisberg (1984).

At the $100 \mathrm{~m}$ level the seasonal cycle in the $u$ component and temperature is very.pronounced with minimum speed and temperature from March to June and maximum speed and temperature from July to October. Beginning mid-September, when the surface temperature begins to increase, the temperature at $100 \mathrm{~m}$ first increases and then decreases and similarly for the $u$-component which is again consistent with a decrease in strength of the easterlies. These simultaneous variations in $u$ and $T$ are consistent with vertical translation of the thermocline with

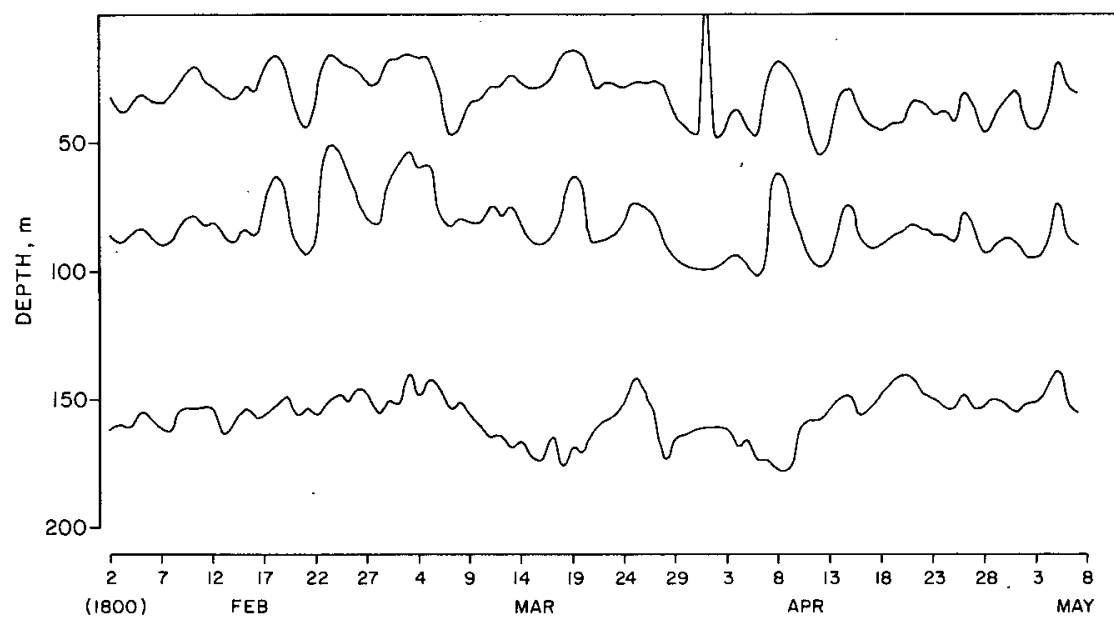

Fig. 4. Positions of the $u$-component's upper and lower $20 \mathrm{~cm} \mathrm{~s}^{-1}$ isotachs and maximum (defining EUC core) as functions of time during the first deployment. 


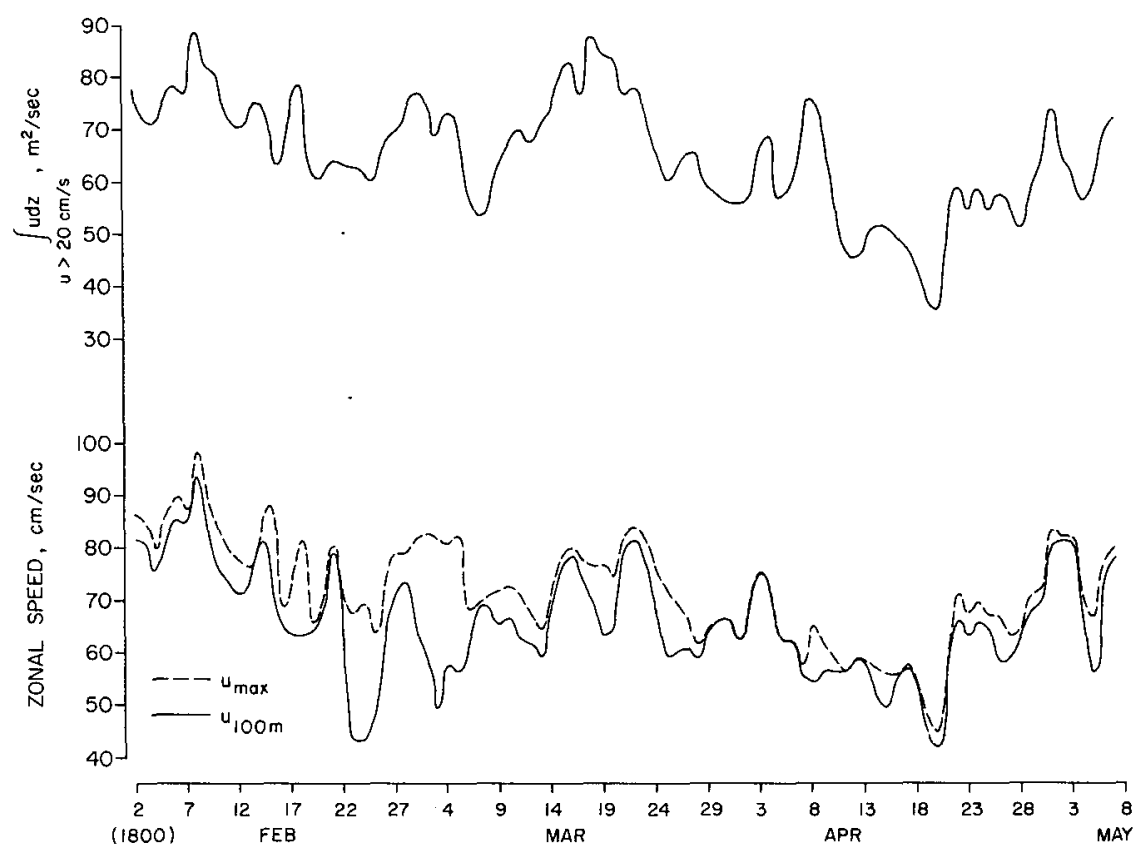

FIG. 5. The $u$-component observed at $100 \mathrm{~m}$ compared with the maximum value estimated at the EUC core depth, and the zonal volume transport per unit width integrated between the upper and lower $20 \mathrm{~cm} \mathrm{~s}^{-1}$ isotachs.

an embedded positive curvature EUC core as discussed previously. Whether or not vertical translation alone can fully account for the increase in speed observed at $100 \mathrm{~m}$ is unclear owing to the limited vertical extent available for translation i.e. the EUC core was always located above $100 \mathrm{~m}$.

The transitional features occuring during June and July at 10 and $100 \mathrm{~m}$ differed not only in time scale (abrupt changes at the surface versus more gradual changes at depth) but also in direction of propagation. Cross correlations and visual alignment of events between records at $24^{\circ} \mathrm{W}$ and $26^{\circ} \mathrm{W}$ suggest westward propagation at $10 \mathrm{~m}$ and eastward propagation at $100 \mathrm{~m}$. Cane (1980) discussed the intensification of the EUC in response to increasing easterly wind stress in terms of a zonal pressure gradient driving force progressing eastward from a western boundary which may have applicability at $100 \mathrm{~m}$.

Although the $v$-component lacks a seasonal cycle, its higher frequency oscillations are seasonally modulated. Figure 6 gives the root-mean-square amplitude of the $v$-component oscillations at the $100 \mathrm{~m}$ level as a function of period (time scale) and time (season) calculated by complex demodulation. The dominant oscillations occuring with time scales of 2-3 weeks have maximum amplitudes during boreal summer when the winds are strongest and minimum amplitudes during early spring when the winds are weakest. A similar modulation also appears at higher frequency. Philander (1978) proposed that these 2-3 week oscil- lations arise via barotropic instability as the surface currents intensify seasonally. At the $10 \mathrm{~m}$ level, $u, v$ and temperature are visually correlated while these oscillations exist. Therefore the abrupt westward propagating thermal and momentum signatures may be due to these seasonally generated instabilities.

\section{Kinematics of the velocity fluctuations}

Kinematical properties of the velocity and temperature fluctuations at the $100 \mathrm{~m}$ level are described by the statistics of Fig. 7. Variance density spectra averaged over a bandwidth of $1.25 \times 10^{-3} \mathrm{cph}$ for a nominal 18 degrees of freedom are given in the upper plate. Note the similarity between the $u$-component and temperature spectra and their dissimilarity with the $v$-component spectrum even though the $u$ and $v$ component energy levels are generally equal. The horizontal velocity hodograph orientation, stability, semi-minor to semi-major axis ratio, maximum and minimum values of coherence squared between the horizontal velocity components, and the coherence squared and phase between the velocity components and temperature follow below the variance spectra. The bandwidth for all of these calculations is 1.25 $\times 10^{-3} \mathrm{cph}$ and the corresponding $90 \%$ significance level for the null hypothesis on coherence squared is given by the dashed lines.

Going from low to higher frequency note the following observations at the $100 \mathrm{~m}$ level. The seasonal 

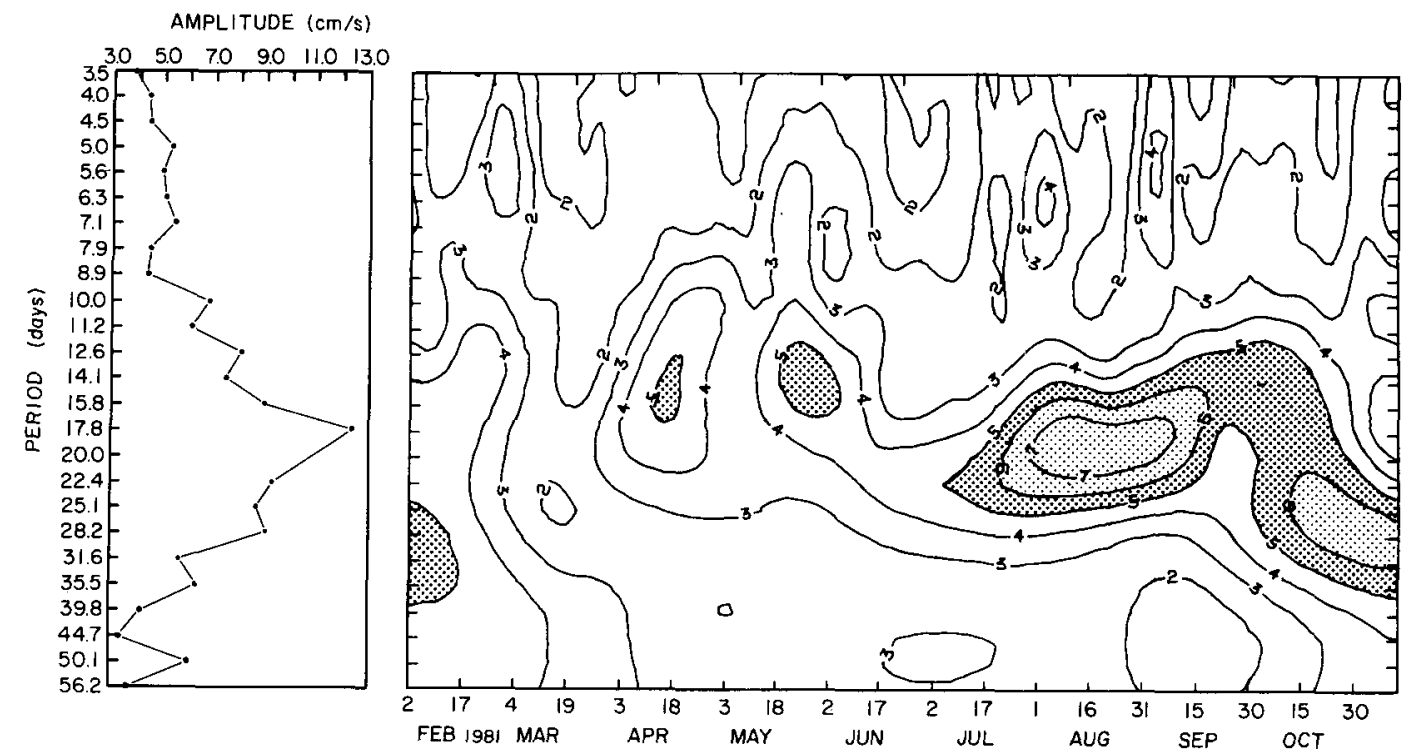

FIG. 6. Amplitude as a function of period (inverse frequency) and time for the $v$-component time series from 100 $\mathrm{m}$ at $26^{\circ} \mathrm{W}$ calculated by complex demodulation. Maximum amplitude is given on the left plate and the seasonal modulation is given on the right plate. Relatively large amplitude regions are highlighted.

cycle appears as a rectilinear (zero axis ratio and simultaneously high maximum and low minimum coherence), zonally oriented ( $\alpha$ equal to zero or one) oscillation with the $u$-component in phase with temperature. Fluctuations at 2-3 week time scales are coherent and rectilinear with meridional $(\alpha=0.5)$ orientation. Zonally oriented rectilinear motions are next observed upon a time scale of 3.5 days. As a general observation temperature is coherent and in phase with $u$ while being incoherent with $v$. While peaks appear in the $u$-component and temperature spectra around time scales of 7 days, the associated oscillations at $100 \mathrm{~m}$ lack stability. Although not shown these oscillations do appear stable and zonally oriented at $150 \mathrm{~m}$.

At the $10 \mathrm{~m}$ level (not shown), the motions also tended to be rectilinear but the orientations were not preferably zonal or meridional. Temperature was coherent with $u$ and to a lesser extent with $v$; however, unlike at the $100 \mathrm{~m}$ and $150 \mathrm{~m}$ levels, $u$ and temperature were $\pi$ radians out of phase; i.e., eastward momentum surges were associated with cooling. This was also the case at the $50 \mathrm{~m}$ level. Referring back to Fig. 2, one observes that the antiphase relationship between $u$ and temperature on the fluctuation time scale is opposite that on the seasonal time scale at 10 $m$. As the SEC intensified from early-May through mid-June, the temperature decreased. It would therefore appear that different mechanisms are controlling the surface mixed layer temperature at seasonal and shorter time scales. At seasonal time scales a surface divergence associated with increasing easterlies and westward accelerating SEC would seem to be the likely candidate. At shorter time scales the correlation between eastward momentum and decreasing temperature implies vertical or meridional advection as the source. Zonal advection at the surface is ruled out since the temperature gradient is too small and oppositely directed.

The pertinent findings of this section are summarized below.

1) Apart from the seasonal cycle an equivalence of energy was found between $u$ - and $v$-components for fluctuations within the EUC. This is in contrast to previous measurements made below the EUC where $v$-component energy dominated over $u$-component energy at time scales greater than 4 days, e.g., Weisberg et al. (1979).

2) Where coherent, the velocity vector fluctuations within the EUC were anisotropic with preferred zonal or meridional orientation. This agrees with the previous equatorial Atlantic findings below the EUC by Horigan and Weisberg (1981).

3) Temperature fluctuations were generally coherent with the $u$-component but not with the $v$-component. At seasonal time scales, temperature and $u$ were in phase at all depths while at shorter time scales the phase reversed across the EUC core implying that vertical motions of the EUC were partially controlling the temperature and $u$-component oscillations.

\section{Vertical structure}

Vertical coherence across the different current regimes was generally low and spatially inhomogeneous. For example, Fig. 8 shows the coherence squared and phase between $v$-component, $u$-component, and tem- 

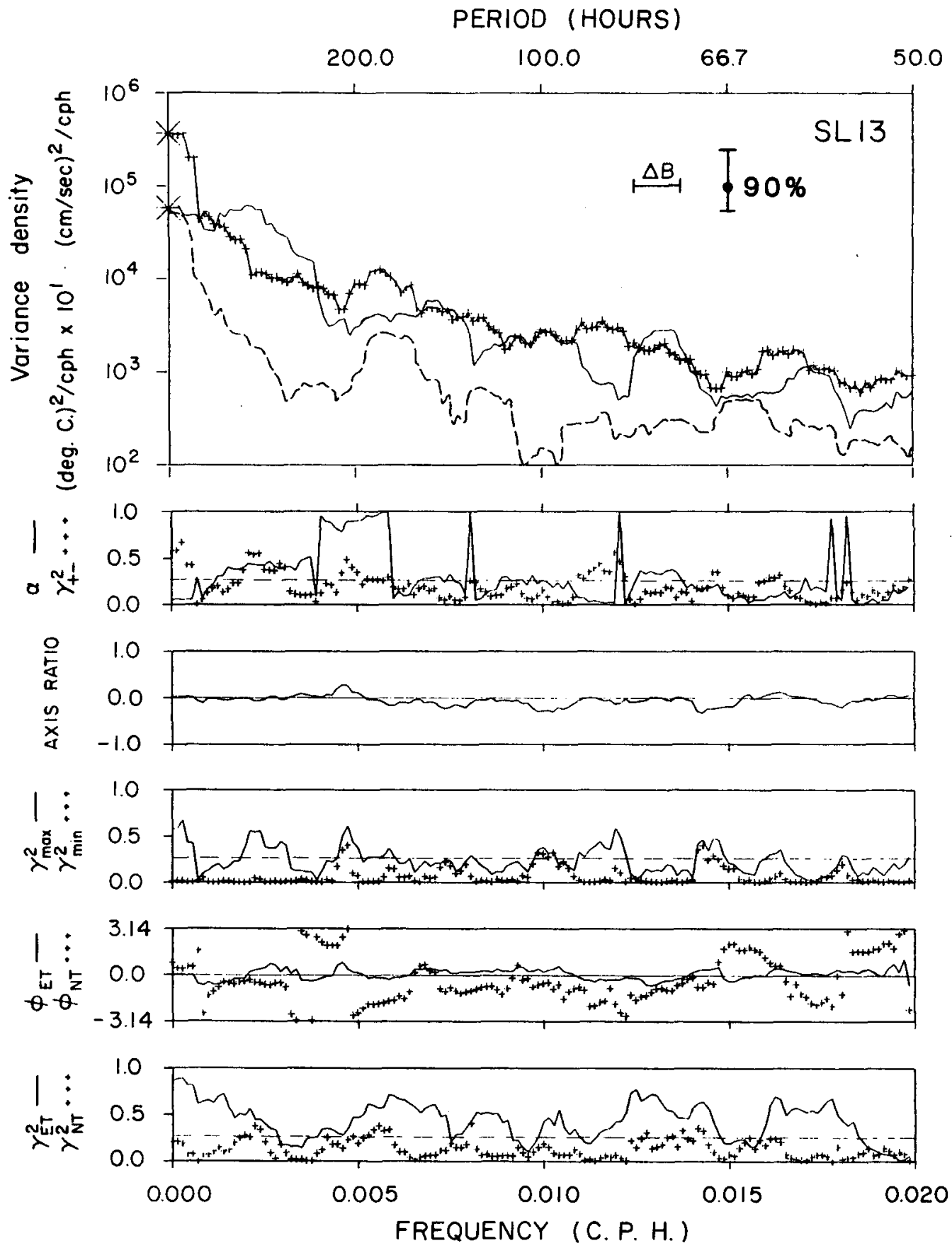

FIG. 7. Variance density spectra for $v$ (solid line), $u$ (solid line with pluses) and temperature (dashed line); horizontal velocity hodograph ellipse stability, $\gamma$; orientation, $\alpha$; semi-minor to semi-major axis ratio (positive and negative denote anticlockwise and clockwise polarization respectively); maximum and minimum cartesian velocity component coherence squared; and velocity component/temperature coherence squared and phase as functions of frequency calculated for the $100 \mathrm{~m}$ level on the equator at $26^{\circ} \mathrm{W}$. Auto and cross spectra were averaged over a bandwidth of $1.25 \times 10^{-3} \mathrm{cph}$ as shown. The null hypothesis $90 \%$ significance levels on coherence squared are given by dashed lines.

perature time series observed at $10 \mathrm{~m}$ and $100 \mathrm{~m}$ at both $26^{\circ} \mathrm{W}$ and $24^{\circ} \mathrm{W}$. At $26^{\circ} \mathrm{W}$ (upper plate), fluctuations in the SEC were generally incoherent with those in the EUC especially for $u$ and temperature. The $v$-component shows some coherence with upward phase propagation in a band centered upon a 6-day time scale and perhaps again around 3 days but these time scales do not correspond to those discussed in the previous section. At $24^{\circ} \mathrm{W}$ over the same depth interval the $v$-components and temperatures were 

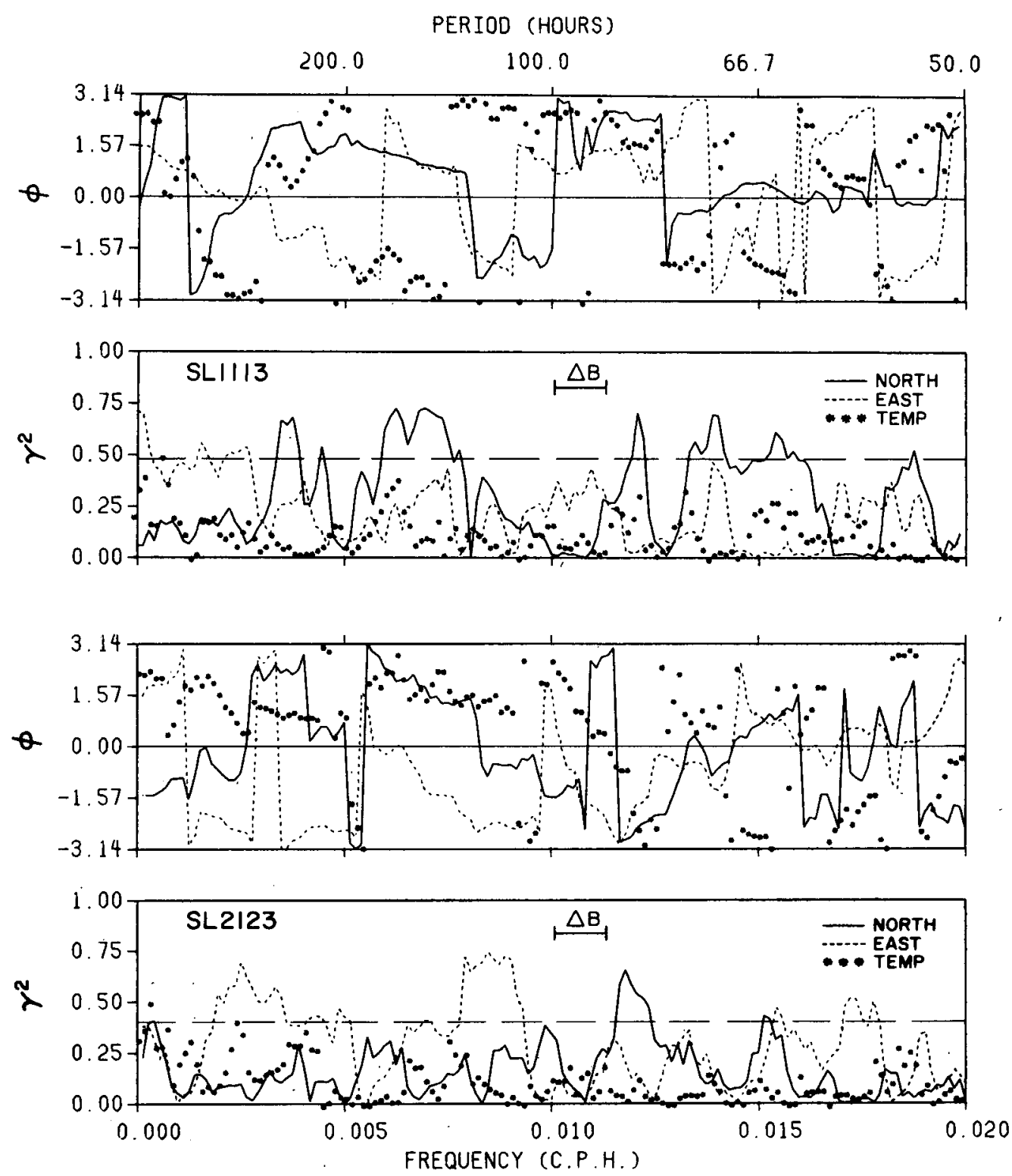

FIG. 8. Coherence squared and phase for $u$-component, $v$-component, and temperature time series observed between $10 \mathrm{~m}$ and $100 \mathrm{~m}$ (across the SEC and EUC) at both $26^{\circ} \mathrm{W}$ and $24^{\circ} \mathrm{W}$. Cross spectra were averaged over a bandwidth of $1.25 \times 10^{-3} \mathrm{cph}$ and the associated null hypothesis $90 \%$ significance levels are given by dashed lines.

incoherent while the $u$-components were coherent and $\pi$ radians out of phase within time scales of 1-3 weeks. This antiphase behavior between $u$-component fluctuations in the SEC and EUC at one longitude but not at another only $224 \mathrm{~km}$ away points out the inhomogeneous nature of the variability. This is not a quirk of the calculation as inspection of the data during May and June in Fig. 2 demonstrates.

Vertical coherence between oscillations within the EUC $(100 \mathrm{~m}$ and $150 \mathrm{~m})$ were generally higher as shown in Fig. 9. The $u$-components and temperatures were coherent with upward phase propagation within a narrow band centered upon 7.5 days. The highest $u$-component coherence appears centered upon 4 days. Interestingly, these vertically most coherent motions did not have the highest stability at either level. Apparently, the $u$-component fluctuations within the EUC at these time scales occurred more regularly than the $v$-components resulting in stronger vertical coherence than anisotropy as measured by ellipse stability. This is also reflected in the relatively low vertical coherence from the $v$-component.

\section{Heat and momentum balances}

Large fluctuations of temperature and momentum in the presence of strong mean currents are suggestive of interactions. Although the array was not intended 

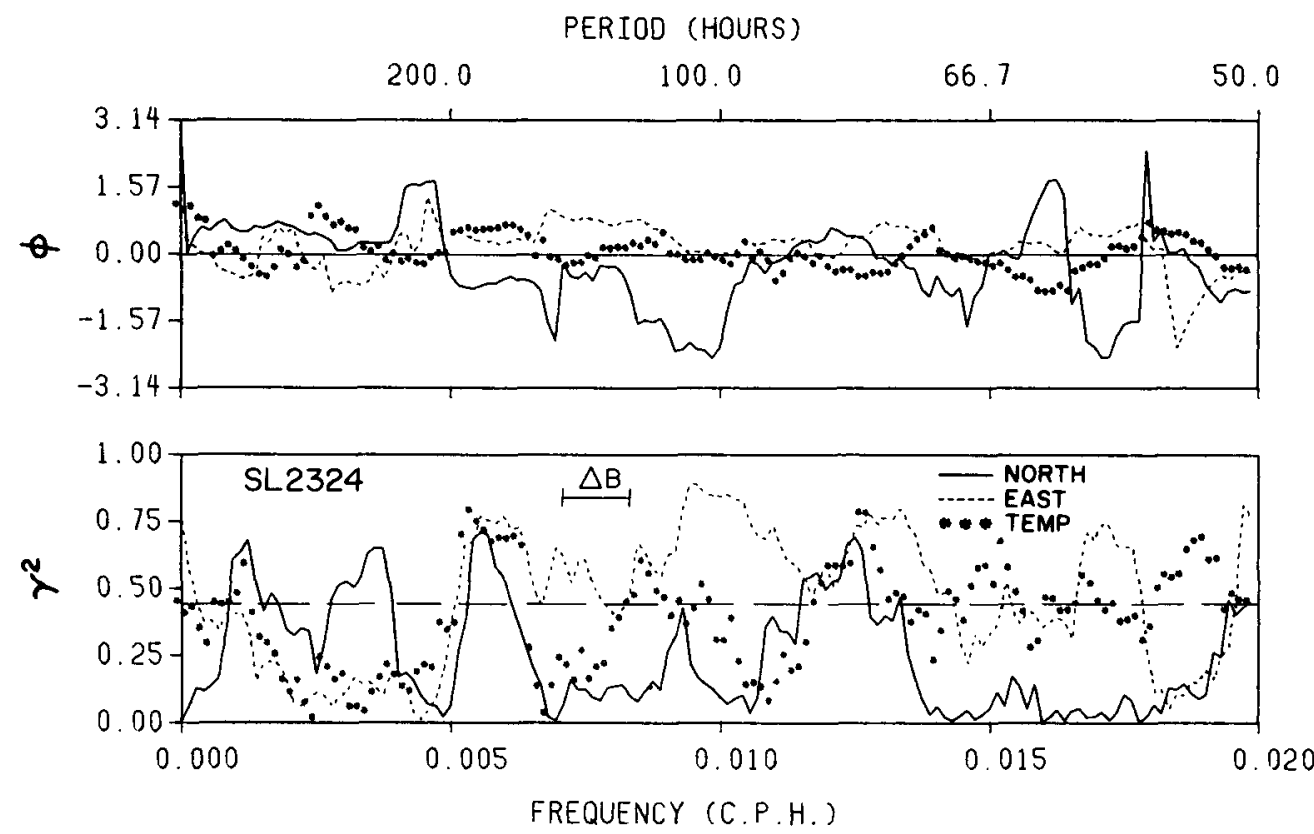

FIG. 9. Coherence squared and phase for $u$-component, $v$-component, and temperature between $100 \mathrm{~m}$ and $150 \mathrm{~m}$ (within the EUC) at $24^{\circ} \mathrm{W}$. Cross spectra were averaged over a bandwidth of $1.25 \times 10^{-3} \mathrm{cph}$ and the associated null hypothesis $90 \%$ significance level is given by the dashed line.

for measuring flux divergences, certain properties of the point measurements and their zonal differences have been examined to assess regions in the water column where linear, linearized, and nonlinear balances are acting. For discussion purposes, linear, linearized and nonlinear refer respectively to the neglect of mean currents, terms first order in perturbation quantities, and terms second order in perturbation quantities (Reynolds fluxes).

Defining the mean as the time average over each particular record and performing the Reynolds averaging, the following was observed for the horizontal contribution to the total derivatives of horizontal momentum in the upper equatorial Atlantic: 1) a linear momentum balance (neglect of mean currents) seems valid away from the surface SEC and the EUC core, 2) linearized terms within the horizontal momentum balance may be important in and above the EUC core, and 3) nonlinear (second order perturbation) terms may be important in the momentum balance of the surface SEC and also in the EUC if off equator values of horizontal Reynolds stress are large.

The horizontal momentum equations also contain vertical advection of momentum terms. How do these compare with the linearized horizontal terms? During the first deployment there was adequate vertical coverage for estimating vertical derivatives of $u$ and $T$ and the perturbation vertical velocity component $w^{\prime}$ may be estimated from:

$$
w^{\prime}=\frac{\partial T^{\prime} / \partial t}{\partial T / \partial z}
$$
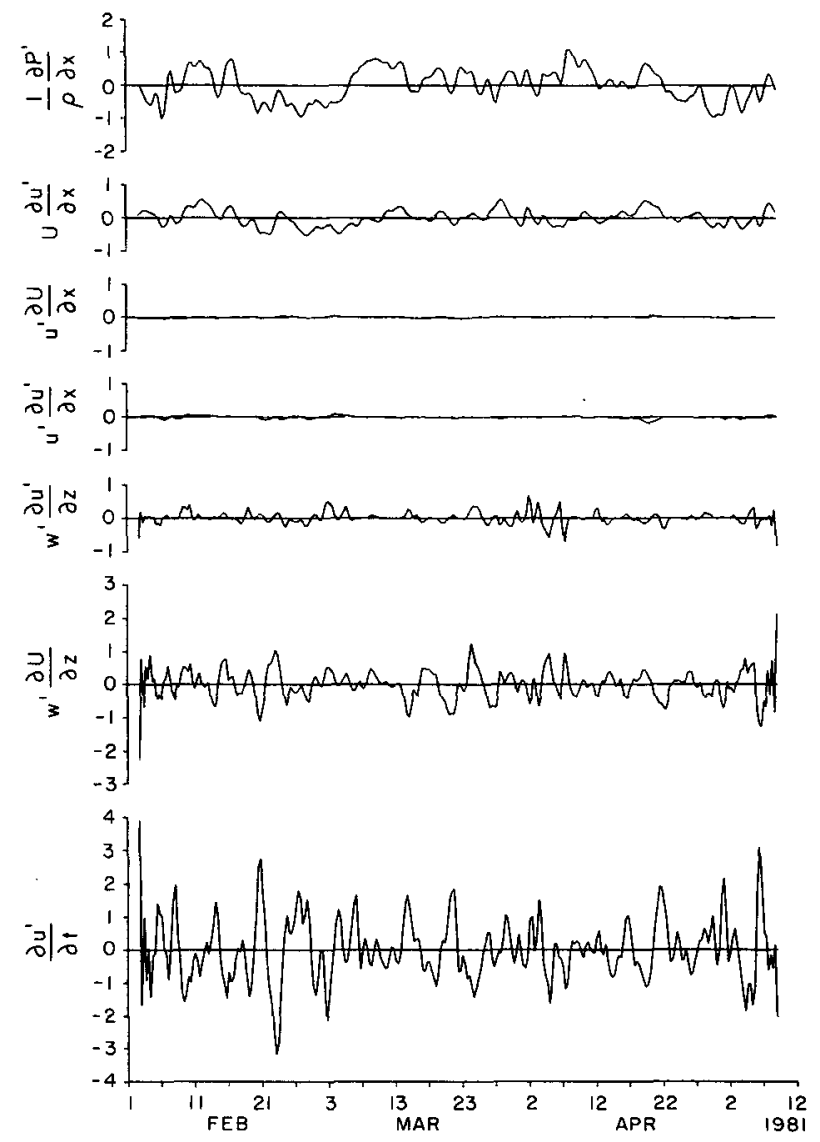

FIG. 10. Terms calculable in the zonal momentum equation from the $100 \mathrm{~m}$ level at $26^{\circ} \mathrm{W}$. Capitals denote mean values and primes denote deviations from those means. Units are $10^{-5} \mathrm{~cm} \mathrm{~s}^{-2}$. 

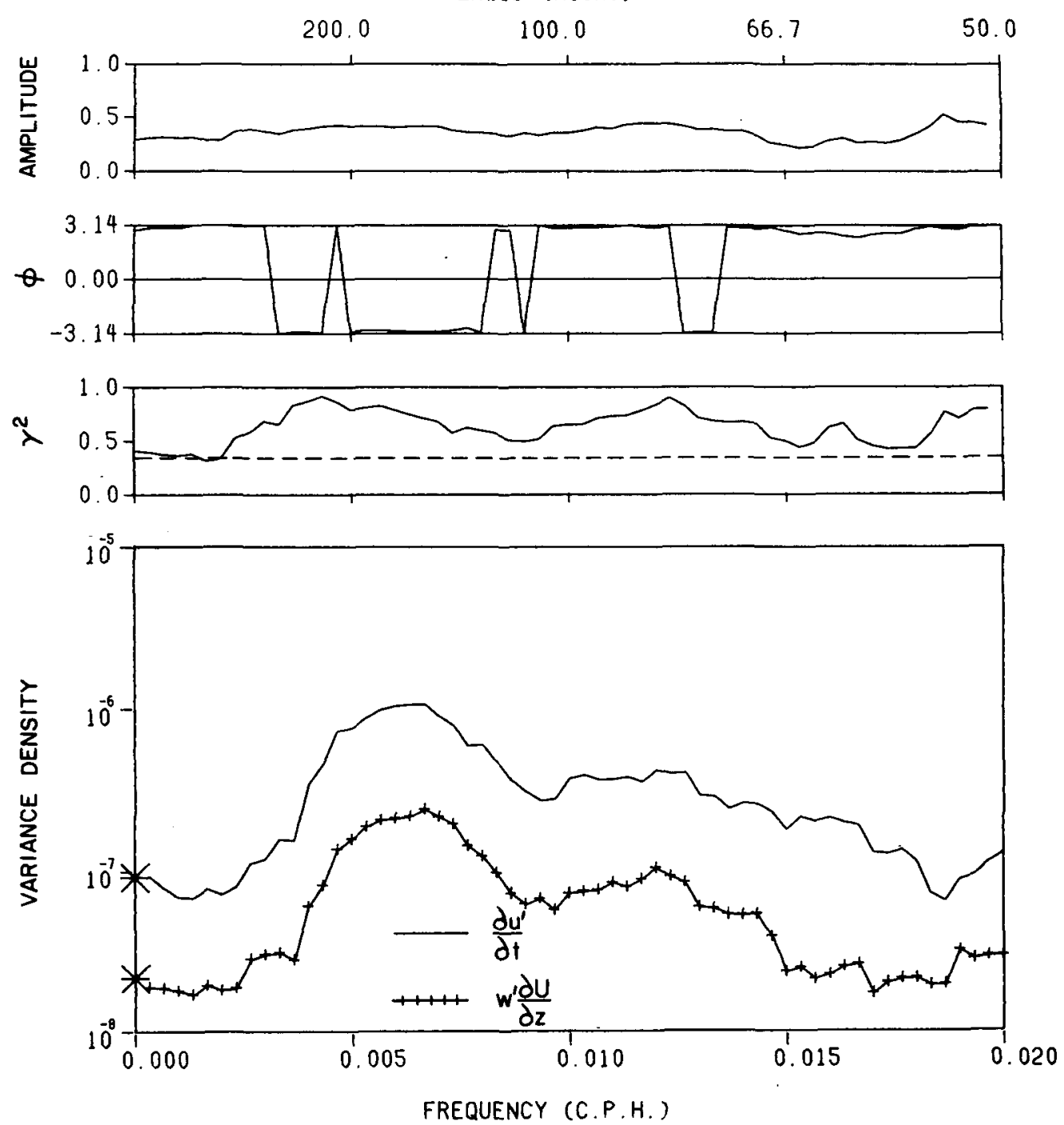

FIG. 11. Variance density for the lower two time series of Fig. 11 and their coherence squared, phase, and transfer function amplitude. The null hypothesis $90 \%$ significance level on coherence squared is given by the dashed line.

where primes denote perturbations and capitals denote mean values. If one assumes that: 1) $V=\partial U / \partial y$ $=0$ by symmetry, 2) $W \ll w^{\prime}$, and 3 ) the omitted nonlinear terms are negligible, then the zonal perturbation momentum equation may be written as

$$
\begin{aligned}
\frac{\partial u^{\prime}}{\partial t}+u^{\prime} \frac{\partial U}{\partial x}+U & \frac{\partial u^{\prime}}{\partial x}+u^{\prime} \frac{\partial u^{\prime}}{\partial x} \\
& +w^{\prime} \frac{\partial u^{\prime}}{\partial z}+w^{\prime} \frac{\partial U}{\partial z}=-\frac{1 \partial P^{\prime}}{\rho \partial x},
\end{aligned}
$$

where $u^{\prime} \partial u^{\prime} / \partial x$ has been retained since it can be estimated. Figure 10 shows each of these terms as a function of time computed at the $100 \mathrm{~m}$ level. The pressure term was calculated by integrating the hydrostatic equation down to $100 \mathrm{~m}$ assuming $\rho=\rho(T)$ only. The terms $u^{\prime} \partial u^{\prime} / \partial x$ and $u^{\prime} \partial U / \partial x$ are negligible. The terms $U \partial u^{\prime} / \partial x$ and $(1 / \rho)\left(\partial P^{\prime} / \partial x\right)$ look similar but bear little if any resemblance to $\partial u^{\prime} / \partial t$ : they appear to vary on longer time scales. Note the resemblance however between $w^{\prime} \partial U / \partial z$ and $\partial u^{\prime} / \partial t$ as well as $w^{\prime} \partial u^{\prime} /$ $\partial z$ which occurs with much smaller amplitude. Figure 11 shows the variance density spectra of $\partial u^{\prime} / \partial t$ and $w^{\prime} \partial U / \partial z$ along with their coherence squared, phase and transfer function amplitude (amplitude ratio for the coherent portions of the spectrum). The spectra look very similar, both peaking over a band centered upon 7.5 days. Coherence is observed for time scales shorter than 20 days, the phase is clearly $\pi$ radians and the transfer function amplitude is approximately 0.4 . Putting $w^{\prime} \partial U / \partial z$ on the forcing side of the zonal momentum equation results in the out of phase relation with $\partial u^{\prime} / \partial t$. These results suggest that a 
significant portion of the zonal velocity component fluctuations observed at $100 \mathrm{~m}$ with time scales of several days to several weeks are due to linearized vertical advection of eastward momentum.

\section{Summary}

Velocity and temperature data from the South Equatorial Current (SEC) and the Equatorial Undercurrent (EUC) collected on the equator at 26 and $24^{\circ} \mathrm{W}$ using surface moorings from February to November 1981 have been shown.

At the $10 \mathrm{~m}$ level the SEC was weak and variable through early May. Eastward flow appeared over brief intervals along with increasing temperature indicative of equatorial convergence and downwelling when climatology would suggest weak and variable surface trade winds. Westward acceleration of the SEC and decreasing temperature followed through June as winds presumably increased resulting in a surface divergence. Westward flow abruptly halted at the end of June, and the temperature dropped. Velocity sensors failed at this level in July but the temperature remained fairly steady through September after which it slowly increased consistent with relaxing trade winds.

The EUC was well developed over the entire experimental duration but its speed and temperature at $100 \mathrm{~m}$ was lowest from March to June. July was transitional with speed increasing by around $50 \%$ and temperature increasing by around $4^{\circ} \mathrm{C}$. Speed and temperature then began to decrease in mid-October.

The seasonal transitions observed at $10 \mathrm{~m}$ and 100 $m$ not only differed in their timing but also in their direction of propagation. At the $10 \mathrm{~m}$ level, the momentum and temperature signatures observed during June when the SEC subsided progressed westward, while at $100 \mathrm{~m}$, the adjustment in the EUC progressed eastward.

Different dynamical mechanisms appear to influence surface mixed layer temperature on seasonal and shorter time scales. On the seasonal time scale, horizontal advection and surface divergence (convergence) associated with increasing (decreasing) easterlies is evident. On shorter time scales, evidence points toward vertical advection as a source of cold water.

Unlike the $u$-component and temperature, the $v$ component lacked a seasonal cycle, its oscillations occurring at higher frequency about zero mean values. These higher frequency oscillations, notably at time scales of 2-3 weeks, were modulated on a seasonal cycle with maximum amplitudes during boreal summer when the winds are strongest and minimum amplitudes during boreal spring when the winds are weakest.

The data suggest that the mean currents play a role in the higher frequency (several day time scales) fluctuations. Coherence was nonhomogeneous. It was lowest across the SEC and EUC and highest below the EUC. Where coherent, the motions tended to be anisotropic with preferred zonal or meridional orientation. Temperature was generally coherent with the $u$-component but not with the $v$-component and the $u$-component energy level relative to the $v$-component was higher than that previously observed below the EUC. This elevation was attributed to vertical advection of mean zonal momentum by the vertical velocity fluctuations.

Acknowledgments. The field program and data analyses were supported by grants from the Oceanography Section, National Science Foundation, initially under OCE-7923335 and subsequently by OCE8211848. A particular note of appreciation is given to Dr. D. Halpern of the U.S. Dept. of Commerce, NOAA-PMEL for sharing his prior experience with similar moorings in the equatorial Pacific and to members of his staff (H. Milburn and G. Duley) for their consultation and advice. Messrs. P. Blankinship and J. Woods of the North Carolina State University assisted with the field work. Mr. J. Blue of the University of Rhode Island prepared the current meters. Mr. J. Hickman and Ms. T. Clay, both of the North Carolina State University, assisted with the computations and graphics respectively as well as going to sea.

\section{REFERENCES}

Cane, M. A., 1980: On the dynamics of equatorial currents, with application to the Indian Ocean. Deep-Sea Res., 27, 525-544.

Garzoli, S. L., and E. J. Katz, 1984: Winds at St. Peter and Paul Rocks during the first SEQUAL year. Geophys. Res. Lett., 11, 715-718.

Hastenrath, S., and P. J. Lamb, 1977: Climatic Atlas of the Tropical Atlantic and Eastern Pacific Ocean. The University of Wisconsin Press, 15 pp., 97 charts.

Hellerman, S., 1979: Charts of the variability of the wind stress over the tropical Atlantic. Deep-Sea Res., 26, (Suppl. II), 6375.

Horigan, A. M., and R. H. Weisberg, 1981: A systematic search for trapped equatorial waves in the GATE velocity data. $J$. Phys. Oceanogr., 11, 497-509.

Katz, E. J., and S. Garzoli, 1982: Response of the western equatorial Atlantic Ocean to an annual wind cycle. J. Mar. Res., 40(Suppl.), 307-327.

- and Collaborators, 1977: Zonal pressure gradient along the equatorial Atlantic. J. Mar. Res., 35, 293-307.

Knox, R. A., and D. Halpern, 1982: Long range Kelvin wave propagation of transport variations in Pacific Ocean equatorial currents. J. Mar. Res., 40(Suppl.), 329-339.

Matsuno, T., 1966: Quasi-geostrophic motions in the equatorial area. J. Meteor. Soc. Japan, 44, 25-43.

Philander, S. G. H., 1978: Instabilities of equatorial currents: Part II. J. Geophys. Res., 83, 3679-3682.

- 1981: The response of equatorial oceans to a relaxation of the trade winds. J. Phys. Oceanogr., 11, 176-189.

- , and R. C. Pacanowski, 1980: The generation and decay of equatorial currents. J. Geophys. Res., 85, 1123-1136.

Weisberg, R. H., 1984: Seasonal adjustments in the equatorial Atlantic during 1983 as seen by surface moorings. Geophys. Res. Lett., 11, 733-735.

-, and A. M. Horigan, 1981: Low-frequency variability in the equatorial Atlantic. J. Phys. Oceanogr., 11, 913-920.

, L. Miller, A. M. Horigan and J. A. Knauss, 1979: Velocity observations in the equatorial thermocline during GATE. Deep-Sea Res., 26(Suppl. II), 217-248. 